\title{
The effect of vitamin concentrates on the flavor of pasteurized fluid milk
}

\author{
E. B. Yeh, ${ }^{*}$ A. N. Schiano, ${ }^{*}$ Y. Jo, ${ }^{*}$ D. M. Barbano, $†$ and M. A. Drake*1 \\ *Department of Food, Bioprocessing and Nutrition Sciences, Southeast Dairy Foods Research Center, North Carolina State University, \\ Raleigh 27695 \\ †Department of Food Science, Northeast Dairy Foods Research Center, Cornell University, Ithaca, NY 14853
}

\begin{abstract}
Fluid milk consumption in the United States continues to decline. As a result, the level of dietary vitamin D provided by fluid milk in the United States diet has also declined. Undesirable flavor(s)/off flavor(s) in fluid milk can negatively affect milk consumption and consumer product acceptability. The objectives of this study were to identify aroma-active compounds in vitamin concentrates used to fortify fluid milk, and to determine the influence of vitamin $\mathrm{A}$ and $\mathrm{D}$ fortification on the flavor of milk. The aroma profiles of 14 commercial vitamin concentrates (vitamins $\mathrm{A}$ and $\mathrm{D}$ ), in both oil-soluble and water-dispersible forms, were evaluated by sensory and instrumental volatile compound analyses. Orthonasal thresholds were determined for 8 key aroma-active compounds in skim and whole milk. Six representative vitamin concentrates were selected to fortify skim and $2 \%$ fat pasteurized milks (vitamin A at 1,500-3,000 IU/qt, vitamin D at 200-1,200 IU/qt, vitamin A and D at 1,000/200-6,000/1,200 IU/qt). Pasteurized milks were evaluated by sensory and instrumental volatile compound analyses and by consumers. Fat content, vitamin content, and fat globule particle size were also determined. The entire experiment was done in duplicate. Water-dispersible vitamin concentrates had overall higher aroma intensities and more detected aroma-active compounds than oil-soluble vitamin concentrates. Trained panelists and consumers were able to detect flavor differences between skim milks fortified with water-dispersible vitamin $\mathrm{A}$ or vitamin $\mathrm{A}$ and $\mathrm{D}$, and unfortified skim milks. Consumers were unable to detect flavor differences in oil-soluble fortified milks, but trained panelists documented a faint carrot flavor in oil-soluble fortified skim milks at higher vitamin A concentrations $(3,000-6,000 \mathrm{IU})$. No differences were detected in skim milks fortified with vitamin $\mathrm{D}$, and no differences were detected in any $2 \%$ milk. These results
\end{abstract}

Received January 18, 2017.

Accepted February 13, 2017.

${ }^{1}$ Corresponding author: maryanne_drake@ncsu.edu demonstrate that vitamin concentrates may contribute to off flavor(s) in fluid milk, especially in skim milk fortified with water-dispersible vitamin concentrates. Key words: milk, vitamin fortification, flavor

\section{INTRODUCTION}

Vitamin fortification of fluid milk has been in use in the United States since the 1930s, initially to prevent rickets (softening of bones) in children (Public Health Service, 1940). Vitamin D is essential for calcium absorption and is involved in the mineralization process required for bone growth. Vitamin D deficiency causes rickets in children and osteomalacia in adults (Ceglia, 2009). Recent studies also suggest that vitamin D plays a role in the prevention of prostate, breast, and colorectal cancers (Bouillon et al., 2006; Garland et al., 2006; Grant et al., 2007; Schwartz and Skinner, 2007). Vitamin A is needed for normal growth, vision, reproduction, and differentiation of epithelial cells. Vitamin A deficiency results in night blindness, xerophthalmia (progressive blindness caused by drying of the cornea of the eye), keratinization (accumulation of keratin in digestive, respiratory and urinary-genital tract tissues), and finally exhaustion and death (Zile and Cullum, 1983).

The United States Food and Drug Administration mandated in the 1990s that fortified fluid milks must be within 100 to $150 \%$ of label claims to address documented variability in vitamin amounts (Public Health Service, 1940). Reduced-fat and skim milks must be fortified with vitamin A at a minimum of 2,000 IU per quart $(946 \mathrm{~mL})$; fortification is optional for whole milk. All fluid pasteurized milk is fortified with vitamin D at a minimum of $400 \mathrm{IU}$ per quart $(946 \mathrm{~mL})$ in the United States. Vitamin fortification is a standard procedure for pasteurized fluid milks in the United States, and vitamin concentrates are added to milk before pasteurization (PMO, 2015). Vitamin concentrates are available in oil-soluble and water-dispersible formulations (Murphy and Newcomer, 2001).

The standard shelf life recommended by manufacturers of commercial vitamin concentrates for fluid 
milk is 1 year at room temperature away from light. Recent work has addressed the stability of vitamin D in milk and other dairy products and has indicated that vitamin $\mathrm{D}$ is stable during processing and storage (Banville et al., 2000; Kazmi et al., 2007; Wagner et al., 2008; Hanson and Metzger, 2010; Tippetts et al., 2012). Vitamin A is unstable in the presence of heat, light, or acids (Yeh et al., 2017). Prolonged heating of milk, butter, or butterfat at high temperatures in the presence of oxygen can decrease vitamin A activity (Mousseron-Cadet, 1971; Hartman and Dryden, 1974).

The specific role of vitamin concentrates with respect to the flavor of fluid milk has not been addressed. A few studies have suggested that added vitamin A imparted a detectable off flavor, particularly in skim and low-fat milk (Weckel and Chicoye 1954; Whited et al., 2002). However, to our knowledge, no published studies have directly evaluated the specific role of the actual vitamin source and the carrier in their flavor contributions to fluid milk. Understanding the flavor contributions of vitamin sources to fluid milk can help the dairy industry strategically position vitamin fortification and enhance fluid milk quality. The objectives of this study were to characterize aroma-active compounds in vitamin concentrates used for fluid milk, and to determine the influence of vitamin A and D fortification on the flavor of milk.

\section{MATERIALS AND METHODS}

\section{Experimental Overview}

Two experiments (experiments 1 and 2) were included in this study. The purpose of experiment 1 was to determine the sensory profiles and key aroma-active volatile compounds in pure vitamin concentrates. To carry out this objective, we performed descriptive analysis, headspace extraction, and quantification of volatile compounds by GC-MS and gas chromatography-olfactometry (GC-O) on 14 different pure vitamin concentrates. Orthonasal threshold testing was then conducted on 8 key aroma compounds identified via GC-O. The purpose of experiment 2 was to determine possible vitamin flavor contributions to fluid milk fortified with vitamin A and D. To carry out this objective, representative vitamin concentrates from experiment 1 were selected to fortify skim and $2 \%$ fat milk to determine if trained panelists or consumers could detect flavor differences with and without vitamin fortification. We evaluated skim and $2 \%$ fat milk because they represent what most consumers purchase, and fat plays a protective role in vitamin degradation, light oxidation, and sensory thresholds of off flavors. If vitamin fortification results in off flavor(s), it will be detected in reduced-fat or skim milk. We also conducted descriptive analysis, volatile compounds analysis, vitamin content analysis, and other proximate analyses.

\section{Commercial Samples and Chemical Standards}

Fourteen commercial vitamin concentrates (vitamins A and D) in both oil and water matrices were obtained in duplicate lots from multiple companies. All concentrates were within $45 \mathrm{~d}$ of manufacture, with $>9$ mo of remaining shelf life. Upon arrival, samples were stored at room temperature in the dark until analysis. All chemical standards were obtained from Sigma Aldrich (Milwaukee, WI).

\section{Vitamin Analysis}

Vitamin analysis was conducted in a laboratory with lighting that had UV filters to prevent light oxidation during extraction and analysis. Vitamin analysis for pure vitamin concentrates was conducted in accordance with the standard method performance requirements for vitamin A (AOAC International, 2012a) and vitamin D (AOAC International, 2012b) in pre-blends, premixes, and pure materials. The concentration of retinyl palmitate (vitamin $\mathrm{A}$ ) and vitamin $\mathrm{D}_{3}$ in the commercial vitamin premixes were confirmed by ultra-performance liquid chromatography (UPLC; Acquity H-Class; Waters Corporation, Milford, MA) with photodiode array (PDA) detection (325 $\mathrm{nm}$ for retinyl palmitate and 265 nm for vitamin $\left.\mathrm{D}_{3}\right)$.

Vitamin A analysis for fortified fluid milk was conducted using AOAC method 2002.06 (AOAC International, 2007b). Briefly, retinyl palmitate from a 2-mL test portion of milk was extracted into $5 \mathrm{~mL}$ of hexane (Sigma Aldrich) containing retinyl acetate $(1.25 \mu \mathrm{g} /$ $\mathrm{mL}$; Sigma Aldrich, St. Louis, MO) as internal standard. Vitamin A palmitate was measured by UPLC with PDA detection $(325 \mathrm{~nm})$. The concentration of retinyl palmitate $(\mu \mathrm{g} / \mathrm{mL})$ was calculated using a relative response factor determined with calibration standards $(0.01-5 \mu \mathrm{g} / \mathrm{mL})$.

Vitamin D analysis was also conducted using AOAC method 2002.05 (AOAC International, 2007a). Briefly, vitamin $\mathrm{D}$ from a $15-\mathrm{mL}$ test portion of milk was saponified by mixing with $10 \mathrm{~mL}$ of $50 \%$ (wt/wt) $\mathrm{KOH}$ (Sigma Aldrich) and $20 \mathrm{~mL}$ of ethanol (Sigma Aldrich) containing 2\% (wt/vol) pyrogallol (Sigma Aldrich), followed by extraction with $20 \%$ (vol/vol) diethyl ether (Sigma Aldrich) in hexane containing vitamin $\mathrm{D}_{2}(0.02$ $\mu \mathrm{g} / \mathrm{mL}$; Sigma Aldrich) as internal standard. Vitamin $\mathrm{D}_{3}$ was measured by UPLC with PDA detection (265 
$\mathrm{nm})$. The concentration of vitamin $\mathrm{D}_{3}(\mu \mathrm{g} / \mathrm{mL})$ was calculated using a relative response factor determined with calibration standards $(0.001-0.05 \mu \mathrm{g} / \mathrm{mL})$. Vitamin analyses of milks were conducted at d 0 and $d 10$ post-processing.

\section{Descriptive Analysis of Aroma of Vitamin Concentrates}

All sensory testing was deemed exempt by the North Carolina State University Institutional Review Board for human subjects. Pure vitamin concentrates were dispensed $(30 \mathrm{~mL})$ directly into 3 -digit-coded $60 \mathrm{~mL}$ lidded soufflé cups (Solo Cup Company, Champaign, IL) for orthonasal aroma evaluation. Orthonasal aroma profiles of the concentrates were evaluated following a 30 min equilibration period; no samples were consumed or placed directly in the mouth. Panelists $(\mathrm{n}=8,6$ women, 2 men, ages $22-49$ yr) each had more than 150 $\mathrm{h}$ of previous experience with the sensory analysis of food aromas and flavors using the Spectrum descriptive analysis method (Meilgaard et al., 2007). For vitamin concentrates, panelists documented the overall aroma effect and aroma intensity of predetermined attributes (carrots, rancid oil, painty, fruity, and citrus). These attributes were selected based on 3 lexicon development sessions of $30 \mathrm{~min}$, conducted before profiling.

\section{Headspace Extraction of Volatile Compounds from Vitamin Concentrates}

$\boldsymbol{G C}$ - $\boldsymbol{M S}$. Volatile compounds were extracted from pure vitamin concentrates by headspace solid-phase microextraction (SPME). All injections were made on an Agilent 7820 GC with 5975 MSD (Agilent Technologies Inc., Santa Clara, CA) with a ZB-5MS column (Zb-5ms $30 \mathrm{~m}$ length $\times 0.25 \mathrm{~mm}$ i.d. $\times 0.25 \mu \mathrm{m}$ film thickness; Phenomenex, Torrance, CA). Sample introduction was accomplished using a CTC Analytics CombiPal Autosampler (Zwingen, Switzerland). Five milliliters of vitamin concentrate and $20 \mu \mathrm{L}$ of internal standard solution (2-methyl-3-heptanone in ether at 81 $\mathrm{mg} / \mathrm{kg}$; Sigma Aldrich) were added to 20-mL SPME vials (Microliter Analytical, Suwanee, GA) in triplicate. Vials were equilibrated for $25 \mathrm{~min}$ at $40^{\circ} \mathrm{C}$ with 4 -s pulses of 250-rpm agitation. A 1-cm SPME fiber (divinylbenzene/carboxen/polydimethylsiloxane; Supelco, Bellefonte, PA) was used for all analyses. The SPME fiber was exposed to the samples for $40 \mathrm{~min}$ at $3.1 \mathrm{~cm}$ depth. The fiber was retracted and injected at $5.0 \mathrm{~cm}$ in the GC inlet for $5 \mathrm{~min}$. Scanning from 30 to 350 $m / z$ was performed to identify compounds of interest. Each lot of each vitamin concentrate was evaluated in triplicate.
$\boldsymbol{G} \boldsymbol{C}$ - $\boldsymbol{O}$. Headspace SPME, followed by GC-O, was conducted to characterize aroma-active compounds extracted from vitamin concentrates. Ten milliliters of vitamin concentrate was added to $40-\mathrm{mL}$ amber vials $(28$ $\times 98 \mathrm{~mm}$; Supelco Inc.) with a stir bar, in duplicate. The vials were heated at $40^{\circ} \mathrm{C}$ for $30 \mathrm{~min}$ with constant stirring. An SPME fiber (divinylbenzene/carboxen/ polydimethylsiloxane; Supelco Inc.) was exposed in each sample at $2 \mathrm{~cm}$ for $30 \mathrm{~min}$. The fiber was then injected on an Agilent 6850 GC flame-ionization detector equipped with an olfactometer port (Agilent Technologies Inc.). The GC method used an initial temperature of $40^{\circ} \mathrm{C}$ for $3 \mathrm{~min}$. The temperature was then increased at a rate of $10^{\circ} \mathrm{C} / \mathrm{min}$ to $150^{\circ} \mathrm{C}$, followed by $30^{\circ} \mathrm{C} / \mathrm{min}$ to $200^{\circ} \mathrm{C}$, and held for $5 \mathrm{~min}$. Samples were evaluated in duplicate on 2 different columns: polar ZB-WAX $(30-\mathrm{m}$ length $\times 0.25$-mm i.d. $\times 0.25$ - $\mu \mathrm{m}$ film thickness; Zebron; Phenomenex Inc.) and a nonpolar ZB-5 (30$\mathrm{m}$ length $\times 0.25-\mathrm{mm}$ i.d. $\times 0.25-\mu \mathrm{m}$ film thickness; Zebron; Phenomenex Inc.). The flame ionization detector sniffing port was held at a temperature of $300^{\circ} \mathrm{C}$, with a helium carrier gas flow of $2 \mathrm{~mL} / \mathrm{min}$, and the port was supplied with humidified air at $30 \mathrm{~mL} / \mathrm{min}$. Each sample was evaluated on each column by 2 highly experienced sniffers (each with $>50 \mathrm{~h}$ previous experience with GCO) who recorded retention time, aroma character, and perceived intensity.

\section{Compound Identification and Quantitation}

For positive identification of aroma-active compounds, retention indices, and mass spectra of unknowns, as well as odor properties, were compared with those of authentic standard compounds analyzed under identical conditions on the GC-MS and GC-O. Tentative identifications were based on comparisons of the mass spectra of unknown compounds with those in the National Institute of Standards and Technology mass spectral database (NIST MS Search 2.0, NIST/EPA/ NIH Mass Spectral Library; http://webbook.nist.gov/ chemistry) or on matching the retention index values of unknowns against those of authentic standards. To calculate retention indices, an alkane series $\left(\mathrm{C}_{8}-\mathrm{C}_{20}\right.$ Fluka Chemie Sigma Aldrich, Switzerland) was used (van den Dool and Kratz, 1963). The area ratio (area of internal standard/area of compound) was multiplied by the concentration of the internal standard to determine the relative abundance of each compound.

\section{Selected Odor-Active Compounds}

Eight volatile compounds identified in vitamin premixes via GC-O were selected for threshold testing based on odor intensity, highest frequency detected, 
and the previously reported literature as vitamin degradation products. The compounds selected were trans,trans-2,4-hexadienal, trans,trans-2,4-heptadienal, isoamyl acetate, $\beta$-cyclocitral, $\alpha$-irone, $\beta$-ionone, $\beta$-phellandrene, and $\beta$-damascone. All chemicals were obtained from Sigma Aldrich (St. Louis, MO).

\section{Orthonasal Threshold Analysis}

A modification of the American Society for Testing and Materials (ASTM) procedure E679-9 (ASTM, 2004), an ascending forced choice method of limits, was used to determine orthonasal threshold values for each compound. Three separate media were tested: deionized water, unfortified skim pasteurized milk, and unfortified pasteurized whole milk. These 3 matrices were selected to compare the effect of a polar matrix, a more nonpolar matrix, and fat on the sensory threshold of each compound. Unfortified skim and whole milks were homogenized and HTST-processed in the pilot plant (described later) and stored at $4^{\circ} \mathrm{C}$ for 1 wk before testing. Deionized water and processed milks were screened for off odors before testing.

Stock solutions of key compounds were prepared in 95\% (wt/vol) methanol (Sigma Aldrich). Methanol was chosen as a solvent instead of ethanol due to its lower odor activity. Aliquots of the stock solutions were placed into each medium (deionized water, unfortified skim milk, and unfortified whole milk). The orthonasal detection thresholds of each of these compounds were evaluated individually in each of the 3 different matrices. Each matrix was tested on a different day. These solutions were serially diluted with the respective diluent (factor of 3), and $30 \mathrm{~mL}$ of each was poured into clean, 3-digit-coded $60 \mathrm{~mL}$ lidded soufflé cups (Solo Cup Co.). Seven ascending series were tested for each compound for each matrix, with a 1-min enforced rest between each series of 3 samples. For each series, blank samples of the appropriate matrix were prepared with the same amount of methanol. The samples for each threshold test were prepared $3 \mathrm{~h}$ before the test to achieve equilibrium for each compound in the sample cup (Leksrisompong et al., 2010). Subjects ( $\mathrm{n}=35$ ) were instructed on the appropriate sniffing procedure before testing, as described by Leksrisompong et al. (2010). Responses were collected using paper ballots. The individual best estimate threshold (BET) was taken as the geometric mean of the last concentration with an incorrect response and the first concentration with a correct response, except for the following sequence: if the subject indicated a "not sure" response for the correct choice, that concentration was increased by a factor of 1.41 to adjust for the possibility of a chance correct response (Leksrisompong et al., 2010). The estimate group BET was taken as the geometric mean of the individual BET values. Orthonasal threshold tests were conducted in duplicate on different days for each compound in each matrix.

\section{Pilot-Plant Manufacture of Vitamin-Fortified Milk}

Six vitamin premixes (vitamin A and D) were selected to fortify milk. Vitamin premixes were selected from each category (oil or water) based on the number of aroma-active compounds and the sensory aroma profile, such that these represented the worst-case scenario (intense sensory aromas and frequency and intensity of aroma-active compounds by GC-O). Raw skim milk and raw cream were obtained from the North Carolina State University Dairy Enterprise System. Raw milk samples were sent to Cornell University for SCC (Somascope; Delta Instruments BV, Drachten, the Netherlands) using a fluorometric flow cytometry method (Wehr and Frank, 2004). Additional proximate analysis on raw milk included coliforms, aerobic plate count, fat content, and total solids content. Coliform count and aerobic plate count were conducted using standard methods (Wehr and Frank, 2004; method numbers 7.070 and 6.040 respectively) with Petrifilm plates (Coliform Count Plates and Aerobic Count Plates; 3M, St. Paul, $\mathrm{MN})$. Plates were incubated at $32^{\circ} \mathrm{C}$ for $24 \mathrm{~h}$ before being counted. Fat and total solids content were measured using a Fourier-transform mid-infrared milk analyzer (LactoScope FTIR; Delta Instruments BV). Raw skim and raw cream were standardized to $2 \%$ fat. Fat content was measured again by mid-infrared milk analyzer (calibrated monthly), using a set of modified milk calibration samples (Kaylegian et al., 2006a,b) with all laboratory mean reference chemistry (Wojciechowski et al., 2016) to confirm proper standardization of $2 \%$ fat milk.

Vitamin concentrates were added to the raw skim or raw $2 \%$ milk. Raw milks were batched as follows: skim control with no vitamin addition, skim with vitamin addition to be used as stock solution; repeat with $2 \%$ milk. A Microthermics EHVH pasteurization unit (Microthermics, Raleigh, NC) with a 2-stage homogenizer (GEA Niro Soavi, Parma, Italy) was used to process the milks. Each batch was preheated to $60^{\circ} \mathrm{C}$, homogenized (first stage at 17.3 MPa and second stage at 3.4 MPa), and pasteurized $\left(73^{\circ} \mathrm{C}\right.$ for $\left.15 \mathrm{~s}\right)$ before cooling to $10^{\circ} \mathrm{C}$. Final products were collected in sanitized milk cans, placed at $4^{\circ} \mathrm{C}$, and tested for complete pasteurization using the alkaline phosphatase test (Wehr and Frank, 2004; method 14.060). Fat content, vitamin content, and microbial quality were determined using the meth- 
ods described previously. Milk fat globule size distribution was measured (Smith et al., 1995; Di Marzo et al., 2016) using a Malvern Mastersizer 3000 (Malvern Instruments, Westborough, MA) operated in the Mastersizer 2000 emulation mode for the $2 \%$ fat milks.

Four different concentrations of vitamin-fortified milk $(1,500,2,000,2,500,3,000 \mathrm{IU}$ per quart) were made for premixes containing only vitamin A. These concentrations were chosen because 2,000 to 3,000 IU per quart of vitamin $\mathrm{A}$ is the target concentration level in retail milk products, and it was necessary to test level just below the target because of reported underfortification of retail milks. Four concentrations $(200,400,800$, or 1,200 IU per quart) were also made for premixes containing only vitamin $\mathrm{D}$. Retail milk products are usually fortified with vitamin D at $400 \mathrm{IU}$ per quart. The chosen concentrations were at 50,100,200, and $300 \%$ of the recommended fortification level (400 IU per quart). Because of increasing interest in fortifying vitamin $\mathrm{D}$ at higher concentrations in fluid milk, we evaluated higher fortification levels. Seven concentrations $(1,000 / 200 \mathrm{IU}$, $1,500 / 300 \mathrm{IU}, 2,000 / 400 \mathrm{IU}, 2,500 / 500 \mathrm{IU}, 3,000 / 600$ IU, 4,000/800 IU, 6,000/1,200 IU per quart of vitamins $\mathrm{A}$ and $\mathrm{D}$, respectively) were made for the premixes containing vitamins $\mathrm{A}$ and $\mathrm{D}$. These concentrations were chosen because the premixes contained a set potency ratio of vitamin $\mathrm{A}$ and $\mathrm{D}$; fortifying at these levels was necessary to cover the ranges for both vitamin $\mathrm{A}$ and $\mathrm{D}$ that were tested individually. Different concentrations of vitamin-fortified milk were made by diluting the stock vitamin pasteurized milk solution with novitamin pasteurized milk and bottled into half-gallon, light-shielded milk jugs (Upstate Niagara Cooperative Inc., Buffalo, NY) and stored in the dark at $4^{\circ} \mathrm{C}$. Vitamin analysis was conducted again to ensure the correct target vitamin concentrations in the final products. Skim and $2 \%$ fat milk for a given vitamin premix replication were processed from the same lot of milk. This process was repeated on different weeks for each premix. The entire experiment was done in duplicate.

\section{Descriptive Analysis}

Descriptive sensory analysis of milk flavor was conducted at $\mathrm{d} 3$ and 10 post-processing on fortified fluid milks with vitamin $\mathrm{A}, \mathrm{D}$, or both, and control milks without vitamins using a trained descriptive sensory panel and an established milk flavor language (Croissant et al., 2007; McCarthy et al., 2017). Panelists (n = 8,6 women, 2 men, ages $22-49$ yr) each had more than $150 \mathrm{~h}$ of previous experience with the sensory analysis of food aromas and flavors using the Spectrum descriptive analysis method (Meilgaard et al., 2007). Fortified milks with and without vitamins were dispensed (60 $\mathrm{mL}$ ) directly into 3-digit-coded 120-mL lidded soufflé cups for evaluation. Preparations were conducted with overhead lights off to avoid exposure to light. Samples were evaluated by each panelist in duplicate. Sensory data were collected using paper ballots. All sensory testing was conducted in accordance with the guidelines of the North Carolina State University institutional review board for human subjects.

\section{Consumer Difference Tests}

Triangle difference tests (ASTM E1885) were conducted for vitamin-fortified milks (vitamin A, oil or water; vitamin $\mathrm{D}$, oil or water; vitamin $\mathrm{A}$ and $\mathrm{D}$, oil or water) with at least 50 milk consumers at d 10 post-processing. All 4 vitamin levels were evaluated for vitamin A concentrate and vitamin D concentrate alone. Four selected vitamin levels were evaluated for premixes containing both vitamin $\mathrm{A}$ and $\mathrm{D}$, and 4 difference tests $(2,000 / 400 \mathrm{IU}, 3,000 / 600 \mathrm{IU}, 4,000 / 800 \mathrm{IU}$, and 6,000/1,200 IU of vitamins A and D, respectively). These vitamin levels were chosen based on consumer results from milks fortified with vitamin A only and vitamin D only premixes. Consumers were not recruited before the panel, and consisted of walk-ins from the North Carolina State University campus. Consumers were informed about the testing via flyers on campus and emails to the online database maintained by the Sensory Service Center (Raleigh, NC). Each consumer was verbally instructed on how a triangle difference test was performed and asked to pick the coded sample they believed was different from the other 2 samples. In addition to verbal training, an instruction text describing the test was also provided at each testing station.

Milks $(88 \mathrm{~mL})$ were served at $4^{\circ} \mathrm{C}$ in $177-\mathrm{mL}$ Styrofoam cups (Dart Container Corp., Mason, MI) with random 3-digit blinding codes. Each panelist was given all 3 samples at once and instructed to taste the samples from left to right (randomized order). Within each set of 3 samples, 1 vitamin level was compared with the control, so a total of 4 difference tests (4 vitamin levels) were conducted for each fat content level (skim and 2\%). A 5-min rest was enforced between each difference test within a fat content level. Consumers returned in the afternoon to complete the other series of samples within a fat content level. Upon completion of each test, panelists were compensated with a $\$ 5$ Target gift card. Compusense Cloud version 7.8 (Compusense, Guelph, ON, Canada) was used for data collection. All consumer testing was conducted in accordance with the guidelines from the North Carolina State University institutional review board for human subjects. 


\section{Quantitation of Selected Volatile Compounds in Fortified Fluid Milk}

The 8 volatile compounds previously identified in vitamin premixes via GC-O were quantified via GC-MS in pasteurized milks. Standards for all 8 compounds were provided by Sigma Aldrich (St. Louis, MO). Volatile compounds were extracted from milks using a novel modified stir bar sorptive extraction approach, which involved swelling polydimethylsiloxane stir bars directly in solvent before extraction (Ochiai et al., 2016). Stir bar sorptive extraction has been shown to further improve resolution and limits of detection for gas chromatography compared with SPME in foods, including milk powders (Prieto et al., 2010; Park et al., 2016). Volatiles in skim milk fortified with 3,000 IU vitamin A were extracted using polydimethylsiloxane stir bars swollen in 4 solvents (dichloromethane, diethyl ether, hexane, and cyclohexane) to identify the best solvent for optimal recovery of the selected volatile compounds. First, $5 \mathrm{~mL}$ of milk was placed into a 10-mL amber screw-top vial (Gerstel Inc., Linthicum, $\mathrm{MD})$. Next, $40 \mu \mathrm{L}$ of internal standard was added (0.81 $\mathrm{mg} / \mathrm{kg}$ 2-methyl-3-heptanone in water; Sigma Aldrich, St. Louis, MO). One polydimethylsiloxane stirbar (10 $\mathrm{mm} \times 0.5 \mathrm{~mm}$ thickness, Gerstel Inc.) bloated with solvent was placed in the vial, sealed, and stirred for 1 $\mathrm{h}$ at $800 \mathrm{rpm}$. After $1 \mathrm{~h}$, the stir bar was briefly rinsed in HPLC-grade water, dried, and placed in a thermal desorption unit autosampler tube (Gerstel Inc.). Compounds were desorbed on to the gas chromatograph thermal desorption unit inlet using an autosampler (MPS Autosampler, Gerstel Inc.). The stir bars were desorbed at $250^{\circ} \mathrm{C}$ for $10 \mathrm{~min}$ (thermal desorption unit, Gerstel, Inc.) and the volatile compounds were cryogenically trapped at $-120^{\circ} \mathrm{C}$ (CIS 4 ; Gerstel Inc.). Cyclohexane provided the best resolution of the solvents evaluated, allowing identification of all 8 compounds, and thus was the solvent and conditions of choice for stir bar sorptive extraction in this study.

Extracted volatile compounds were analyzed by GCMS. An Agilent 7890B gas chromatograph (Agilent Technologies Inc.) with an inert mass selective detector (model 5970A, Agilent) with a ZB-Semivolatiles column $(30 \mathrm{~m} \times 0.25 \mathrm{~mm} \times 0.25 \mu \mathrm{m}$; Phenomenex, Torrance, CA) was used to identify and quantify the selected volatile compounds. Initial gas chromatograph oven conditions were $40^{\circ} \mathrm{C}$ for $3 \mathrm{~min}$, with ramp rates of $10^{\circ} \mathrm{C} / \mathrm{min}$ to $90^{\circ} \mathrm{C}, 5^{\circ} \mathrm{C} / \mathrm{min}$ to $200^{\circ} \mathrm{C}$ held for 10 min, and $20^{\circ} \mathrm{C} / \mathrm{min}$ to $250^{\circ} \mathrm{C}$ held for $5 \mathrm{~min}$. Purge time was set to 1.2 min using helium as the carrier gas at a constant flow rate of $1 \mathrm{~mL} / \mathrm{min}$. Compounds were identified by comparison with the 2014 NIST mass spectral library (NIST, 2014), retention index, and retention time of authentic standards injected under identical conditions. The relative abundance of selected compounds was calculated using recovery of the internal standard.

\section{Statistical Analysis}

Statistical analysis was conducted using XLSTAT version 2015.1.01 (Addinsoft, New York, NY). For threshold BET values, the delta method was used for pair-wise comparison of group BET values among different matrices using the formula

$$
Z=\left(\mathrm{BET}_{2}-\mathrm{BET}_{1}\right) / \sqrt{\left(S E_{1}^{2}-S E_{2}^{2}\right)}
$$

where SE is standard error (Leksrisompong et al., 2010). Consumer difference data were determined using the minimum correct judgment for significance at $\alpha$ $=0.05$ (ASTM E1885). Descriptive analysis and volatile compound analysis data were analyzed by 1-way ANOVA using a general linear model with Fisher's least significant difference for means separation. All data were analyzed at a significance level of 0.05 .

\section{RESULTS AND DISCUSSION}

\section{Experiment 1}

Instrumental Volatile and Descriptive Analysis. The concentrations of retinyl palmitate (vitamin A) and vitamin $\mathrm{D}_{3}$ in the commercial vitamin premixes were confirmed to have purities of 99.1 and $98.9 \%$, respectively, by UPLC with PDA detection $(325 \mathrm{~nm}$ for retinyl palmitate and $265 \mathrm{~nm}$ for vitamin $\mathrm{D}_{3}$ ). Trained panel profiling demonstrated that the aroma attributes of the vitamin concentrates were distinct and characterized by carrot, fruity, citrus, rancid oil, and painty aromas. Vitamin A and vitamin A and D concentrates were associated with carroty aromas, and vitamin D concentrates were associated with rancid oil and painty aromas. Vitamin concentrates in water matrices had higher overall aroma intensities than vitamin concentrates in oil matrices $(P<0.05$; Table 1$)$.

Instrumental results were consistent with sensory results; the vitamin concentrates with more odor-active compounds were also associated with higher overall aroma intensity (Table 1). We detected more odor-active compounds in water-dispersible vitamin concentrates, also consistent with higher overall aroma intensities in these concentrates by sensory analysis (Table 1). We detected 43 odor-active compounds in the vitamin concentrates by headspace SPME GC-O. Of those, 32 were identified by aroma, retention index, and mass 
spectra, 7 were tentatively identified by retention index and odor quality, and 4 were unknown (Table 2).

Among the odor-active compounds were acids, alcohols, aldehydes, ketones, esters, and terpenes. Alcohols such as Z-3-hexen-1-ol, and aldehydes hexanal, octanal, heptanal, E, Z-2,4-heptadienal, 2,4-nonadienal, and E2 -octenal, have been identified as the aroma odor compounds of sunflower oil and oxidized sunflower oil (Keszler et al., 1998, 2000; van Ruth et al., 2000; Doleschall et al., 2003), and in other plant oil oxidative degradation products (Snyder et al., 1985; Solinas et al., 1987; St Angelo, 1996; Vichi et al., 2003). These volatiles are products of the oxidation of linoleic acid, the major unsaturated fatty acid in sunflower oil (Grosch, 1987; Frankel, 1983, 1985). We detected these volatiles in oilsoluble vitamin concentrates, which suggested that the source of these compounds could be the carrier of the concentrate - sunflower oil or corn oil.

Ketones $\beta$-ionone, $\alpha$-irone, and $\beta$-damascone, as well as terpenes $\beta$-phellandrene, $\beta$-cyclocitral, $\beta$-cyclohomocitral, and $\alpha$-copaene, have been reported as odor-active aroma compounds in essential oils, tobacco, tea, fruits, vegetables, and wine (Friedrich and Acree, 2002; Winterhalter and Rouseff, 2002; Nielsen and Poll, 2006), and as vitamin A thermal oxidation products (Suyama et al., 1983; Enzell, 1985; Kanasawud and Crouzet, 1990; Crouzet and Kanasawud, 1992; Kim et al., 2000) and vitamin A light oxidation products (Budowski and Bondi, 1960; Gaylord et al., 1986; Litzenburger and Bernhardt, 2016). We detected these volatiles mostly in vitamin A concentrates, and in vitamin $\mathrm{A}$ and $\mathrm{D}$ concentrates, suggesting that they were degradation products from vitamin A in the premixes. Some of the aldehydes we detected in vitamin D concentrates were heptanal, E-2-heptenal, trans,trans-2,4-hexadienal, and trans,trans-2,4-heptadienal; these volatiles have been reported as byproducts of vitamin D oxidation (Kutsky, 1981; DeMan, 1999; King and Min, 2002).

We detected isoamyl acetate in vitamin concentrates that contained ascorbic acid as an antioxidant. Isoamyl acetate is an enzymatic degradation product of ascorbic acid (Hooper and Ayres, 1950; Obretenov et al., 2002). This ester may have come directly from the ascorbic acid added to the vitamin premixes. Other odor compounds, including toluene, styrene, and dodecane, have been reported in food packaging material, specifically in polyethylene (Bravo et al., 1992; Karatapanis et al., 2006). These volatiles may be sourced from the packaging of vitamin premixes, which are commercially packaged in plastic material.

We detected 38 compounds in water-dispersible vitamin concentrates, and 23 compounds in oil-soluble concentrates. Oil matrices have been found to have protective effects with respect to vitamin A stability by delaying oxidative degradation and degradation components (Dary and Mora, 2002; Loveday and Singh, 2008). Vitamin D in plant oils is resistant at high temperatures and during long-term storage. In contrast, vitamin D in non-lipid environments is susceptible to oxidation agents, forming 5,6-trans-vitamin $\mathrm{D}$, which has only $10 \%$ to $30 \%$ vitamin activity (DeMan, 1999; King and Min, 2002). We detected fewer aroma compounds in oil-soluble vitamin concentrates due to the protective

Table 1. Sensory aroma profiles and frequency of aroma-active events detected by gas chromatography-olfactometry of commercial vitamin concentrates from multiple companies

\begin{tabular}{|c|c|c|c|c|c|c|c|c|}
\hline Vitamin type & $\begin{array}{l}\text { Sample } \\
\text { code }\end{array}$ & $\begin{array}{l}\text { Frequency of aroma- } \\
\text { active events }\end{array}$ & $\begin{array}{l}\text { Overall } \\
\text { aroma }^{2}\end{array}$ & Carrots & $\begin{array}{l}\text { Rancid } \\
\text { oil }\end{array}$ & Painty & Fruity & Citrus \\
\hline $\mathrm{D}$ in water & 549 & 26 & $4.5^{\mathrm{a}}$ & $\mathrm{ND}^{3}$ & $3.0^{\mathrm{a}}$ & $4.5^{\mathrm{a}}$ & $1.8^{\mathrm{a}}$ & $1.5^{\mathrm{b}}$ \\
\hline $\mathrm{D}$ in water & 124 & 17 & $3.0^{\mathrm{b}}$ & ND & $3.0^{\mathrm{a}}$ & $4.5^{\mathrm{a}}$ & $1.5^{\mathrm{b}}$ & $1.5^{\mathrm{b}}$ \\
\hline D in oil & 054 & 4 & $1.5^{\mathrm{e}}$ & ND & $1.5^{\mathrm{b}}$ & $1.0^{\mathrm{d}}$ & $1.0^{\mathrm{c}}$ & $1.0^{\mathrm{c}}$ \\
\hline D in oil & 832 & 6 & $1.5^{\mathrm{e}}$ & ND & $1.3^{\mathrm{b}}$ & $1.0^{\mathrm{d}}$ & $1.0^{\mathrm{c}}$ & $1.0^{\mathrm{c}}$ \\
\hline A in water & 007 & 26 & $4.5^{\mathrm{a}}$ & $4.5^{\mathrm{a}}$ & ND & ND & $2.0^{\mathrm{a}}$ & $2.0^{\mathrm{a}}$ \\
\hline A and D in oil & 817 & 9 & $3.0^{\mathrm{b}}$ & $3.0^{\mathrm{b}}$ & $1.0^{\mathrm{c}}$ & $1.0^{\mathrm{d}}$ & $1.3^{\mathrm{bc}}$ & $1.3^{\mathrm{bc}}$ \\
\hline A and D in oil & 428 & 10 & $2.5^{\mathrm{c}}$ & $2.5^{\mathrm{c}}$ & $1.0^{\mathrm{c}}$ & $1.1^{\mathrm{d}}$ & $1.0^{\mathrm{c}}$ & $1.1^{\mathrm{c}}$ \\
\hline A and D in oil & 611 & 12 & $3.0^{\mathrm{b}}$ & $3.0^{\mathrm{b}}$ & $1.3^{\mathrm{b}}$ & $1.0^{\mathrm{d}}$ & $1.8^{\mathrm{a}}$ & $1.0^{\mathrm{c}}$ \\
\hline A and D in oil & 399 & 9 & $3.0^{\mathrm{b}}$ & $3.0^{\mathrm{b}}$ & $1.1^{\mathrm{c}}$ & $1.0^{\mathrm{d}}$ & $1.5^{\mathrm{b}}$ & $1.0^{\mathrm{c}}$ \\
\hline $\mathrm{A}$ and $\mathrm{D}$ in oil & 450 & 8 & $2.0^{\mathrm{d}}$ & $2.0^{\mathrm{d}}$ & $1.1^{\mathrm{c}}$ & $1.8^{\mathrm{c}}$ & $1.0^{\mathrm{c}}$ & $1.5^{\mathrm{b}}$ \\
\hline
\end{tabular}

${ }^{\mathrm{a} e}$ Means in a column with a different letter differ $(P<0.05)$.

${ }^{1}$ Frequency of odor-active compounds detected in pure vitamin concentrates by gas chromatography-olfactometry using headspace solid-phase microextraction.

${ }^{2}$ Aroma intensities were scored on a universal intensity scale of 0 to 15 (Meilgaard et al., 2007).

${ }^{3} \mathrm{ND}=$ not detected. 


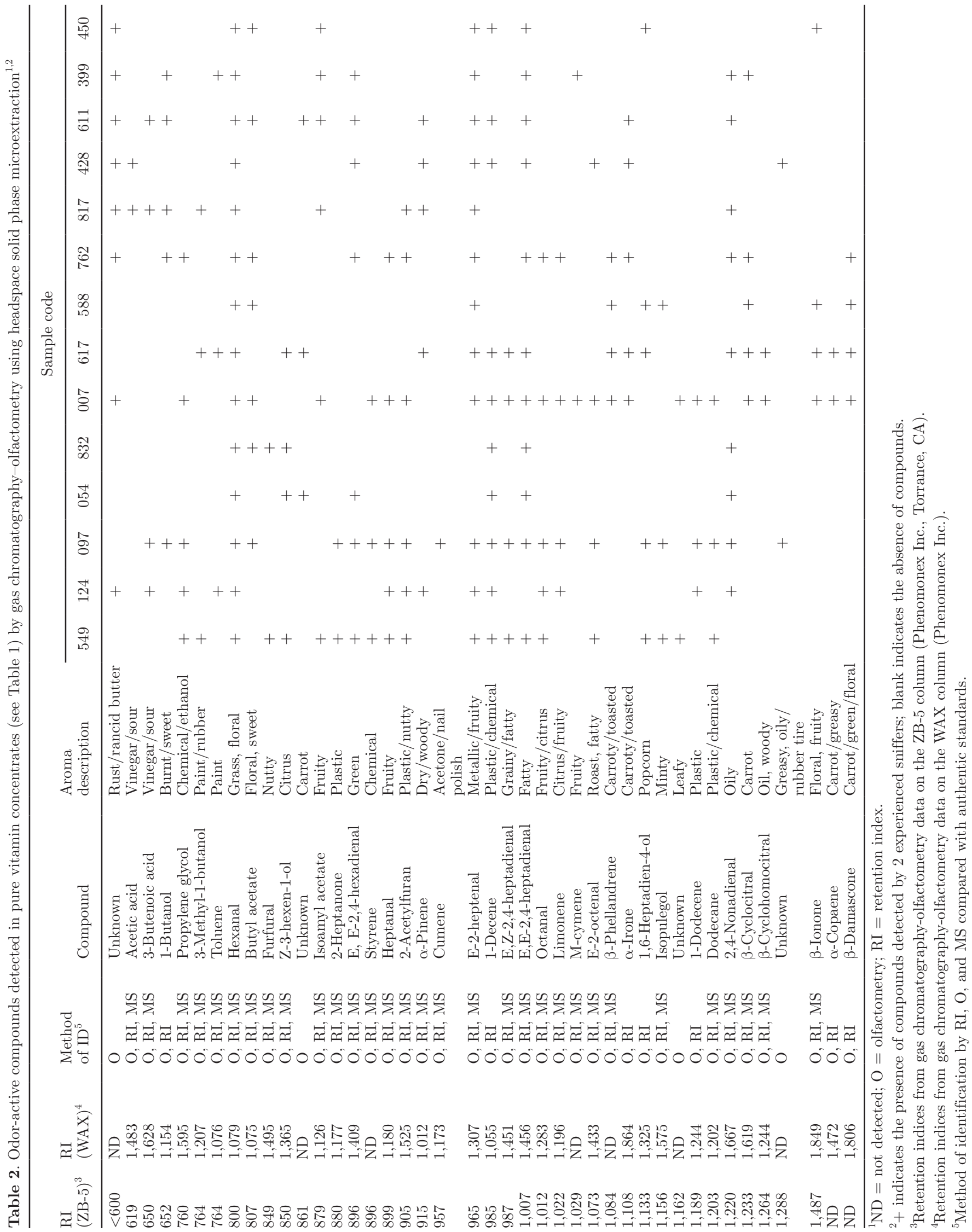


effects of oil matrices in these concentrates by delaying or preventing oxidative degradation of vitamin $\mathrm{A}, \mathrm{D}$, or both. The key volatile compounds found in these vitamin concentrates, based on highest frequency detected and previously reported as vitamin degradation products, were $\beta$-damascone, $\beta$-ionone, $\beta$-phellandrene, isoamyl acetate, $\beta$-cyclocitral, $\alpha$-irone, trans,trans-2,4hexadienal, and trans,trans-2,4-heptadienal.

Orthonasal Threshold Analysis. The BET values of the 8 key volatile compounds from vitamin concentrates were affected by matrix (Table 3). All 8 compounds were hydrophobic and had higher BET values in whole milk than in water or skim milk $(P<0.05)$. This was expected, because hydrophobic compounds are more attracted to the fat in the milk matrix, so less compound is driven into the headspace, increasing the threshold value. Milk also contains protein, which binds organic compounds and forces the equilibrium more into solution, further increasing the threshold. Previous studies have demonstrated that the aroma intensity and headspace concentration of hydrophobic compounds were more affected by the presence of fat than those of hydrophilic compounds (Roberts et al., 2003; Leksrisompong et al., 2010; Kim et al., 2011). Collectively, these threshold results suggested that fat reduction has an influence on threshold and possibly on the flavor release and perception of these compounds.

\section{Experiment 2}

Raw milk aerobic plate counts averaged $190 \mathrm{cfu} / \mathrm{mL}$ and coliforms averaged $31 \mathrm{cfu} / \mathrm{mL}$. The HTST skim and $2 \%$ milks averaged $<20 \mathrm{cfu} / \mathrm{mL}$ aerobic plate counts, and $<1 \mathrm{cfu} / \mathrm{mL}$ coliform counts. Skim milk composition was $0.061 \%$ fat and $9.11 \%$ solids. The $2 \%$ fat milks averaged $1.99 \%$ fat and $10.93 \%$ solids. Milk composition was not different between treatments at each fat level. The SCC was consistently low across all replications $(<200,000)$. The maximum diameter that $90 \%$ of the particles are below $[\mathrm{d}(0.9)]$ for milk fat particle size was $<1.5 \mu \mathrm{m}$ for all milks, indicating appropriate homogenization. We detected no differences in milk fat particle size among the $2 \%$ milks (data not shown). All milks were negative for alkaline phosphatase, indicating complete pasteurization. Vitamin A and D analysis for each target concentration at each time point was consistent, and no degradation over storage was detected (data not shown). These results were consistent with previous studies, which also reported no significant change in vitamin D during $21 \mathrm{~d}$ storage of HTST $2 \%$ milk, UHT $2 \%$ chocolate milk, and low-fat yogurt (Hanson and Metzger, 2010). Vitamin D was not affected by HTST processing (Wagner et al., 2008) and was stable during storage of the milk at $4^{\circ} \mathrm{C}$ (Renken and Warthesen, 1993). We found no significant change in vitamin A content during $24 \mathrm{~h}$ storage of fortified milk in the absence of light (Brothersen et al., 2016), and vitamin $\mathrm{A}$ in unexposed skim milk was more stable than vitamin A in the light-exposed milk (Fellman et al., 1991; Whited et al., 2002).

Descriptive Analysis. Trained panelists detected faint carrot flavor in the highest-level vitamin A skim milk treatments $(3,000$ IU) from oil-based vitamin concentrate (mean $=0.8$ on a scale of 0 to 15$)$, and a higher intensity $(P<0.05)$ of carrot flavor in skim milk treatments with water-dispersible concentrate $(3,000$ $\mathrm{IU}$; mean $=1.5$ on a scale of 0 to 15$)$. Panelists detected a faint carrot flavor in skim milk with vitamin $\mathrm{A}$ and D water-dispersible concentrate at 2,000/400 IU and $2,500 / 500 \mathrm{IU}($ mean $=0.8)$, and a higher intensity $(P<$

Table 3. Best estimate threshold (BET) values for each odorant in water, unfortified skim milk, and unfortified whole milk

\begin{tabular}{|c|c|c|c|}
\hline \multirow[b]{2}{*}{ Compound } & \multicolumn{3}{|c|}{$\mathrm{BET}^{1}(\mathrm{mg} / \mathrm{kg} \pm \mathrm{SE})$} \\
\hline & Water & Skim milk & Whole milk \\
\hline \multicolumn{3}{|l|}{ Ester } & $0.030^{\mathrm{a}} \pm 0.009$ \\
\hline \multicolumn{4}{|l|}{ Ketones } \\
\hline$\alpha$-Irone & $0.002^{\mathrm{c}} \pm 0.001$ & $0.116^{\mathrm{b}} \pm 0.034$ & $3.160^{\mathrm{a}} \pm 0.954$ \\
\hline$\beta$-Ionone & $0.004^{\mathrm{c}} \pm 0.002$ & $0.044^{\mathrm{b}} \pm 0.020$ & $1.915^{\mathrm{a}} \pm 0.963$ \\
\hline$\beta$-Damascone & $0.031^{\mathrm{b}} \pm 0.055$ & $0.012^{\mathrm{b}} \pm 0.006$ & $0.199^{\mathrm{a}} \pm 0.008$ \\
\hline \multicolumn{4}{|l|}{ Terpenes } \\
\hline$\beta$-Phellandrene & $0.027^{\mathrm{b}} \pm 0.006$ & $0.033^{\mathrm{b}} \pm 0.009$ & $0.944^{\mathrm{a}} \pm 0.126$ \\
\hline$\beta$-Cyclocitral & $0.032^{\mathrm{c}} \pm 0.011$ & $0.108^{\mathrm{b}} \pm 0.025$ & $0.846^{\mathrm{a}} \pm 0.251$ \\
\hline \multicolumn{4}{|l|}{ Aldehydes } \\
\hline E,E-2,4-hexadienal & $0.178^{\mathrm{b}} \pm 0.027$ & $0.114^{\mathrm{b}} \pm 0.093$ & $0.284^{\mathrm{a}} \pm 0.054$ \\
\hline E,E-2,4-heptadienal & $0.066^{\mathrm{b}} \pm 0.023$ & $0.250^{\mathrm{a}} \pm 0.072$ & $0.344^{\mathrm{a}} \pm 0.109$ \\
\hline
\end{tabular}


0.05 ) of carrot flavor at $3,000 / 600 \mathrm{IU}, 4,000 / 800 \mathrm{IU}$ and $6,000 / 1,200 \mathrm{IU}$ (mean $=1.3,1.6$, and 2.0, respectively). They also detected faint carrot flavor in skim milks containing vitamin $\mathrm{A}$ and $\mathrm{D}$ oil-based concentrate at $6,000 / 1,200 \mathrm{IU}($ mean $=0.9)$. None of the carrot flavors detected in skim milk were detected in $2 \%$ milk (data not shown). No distinct flavor(s) associated with vitamin $\mathrm{D}$ were detected in skim or $2 \%$ milk with oil-based or water-dispersible vitamin $\mathrm{D}$ concentrate (data not shown).

Consumer Difference Tests. Consistent with trained panel results, consumers could detect differences $(P<0.05)$ in skim milk fortified with waterdispersible vitamin $\mathrm{A}$ at 2,000, 2,500 and 3,000 IU compared with unfortified skim milk (Table 4). They detected no differences in skim milks fortified with vitamin D (Table 5). Several studies on the stability of vitamin $\mathrm{D}$ in milk and other dairy products have indicated that vitamin $\mathrm{D}$ is stable during processing and storage (Banville et al., 2000; Kazmi et al., 2007; Wagner et al., 2008; Hanson and Metzger, 2010). In contrast, vitamin A is unstable in the presence of heat, light, or acids (Mousseron-Cadet, 1971), and prolonged heating of milk, butter, or butterfat at high temperatures in the presence of oxygen can decrease vitamin A activity (Hartman and Dryden, 1974). Breakdown products may contribute to perceptible flavors. Numerous studies have reported that vitamin $\mathrm{A}$ and $\mathrm{D}$ are stable during HTST processing and storage in the absence of light and acid (Hartman and Dryden, 1974; Banville et al., 2000; Kazmi et al., 2007; Wagner et al., 2008; Hanson and Metzger, 2010). In other words, HTST processing has little effect on vitamin A and D degradation, so off flavor(s) detected in skim milk may come from the vitamin concentrates directly.

Consumers were also able to detect differences in skim milk fortified with water-dispersible vitamin A and $\mathrm{D}$ at 2,000/400 IU, 3,000/600 IU, 4,000/800 IU, and 6,000/1,200 IU compared with unfortified skim milk (Table 6 ). They detected no differences among $2 \%$ milks (data not shown). These results were consistent with the results of the descriptive analysis, and the difference test results from milks fortified with only vitamin A. This was likely due to the protective effects of milk fat on the sensory thresholds of off flavors; orthonasal thresholds of nonpolar compounds are reduced in lower-fat or fat-free dairy matrices compared with whole milk or higher-fat products (Leksrisompong et al., 2010; Kim et al., 2011). Previous studies have also suggested that added vitamin A concentrate imparted a detectable off flavor, particularly in skim and low-fat milk, and occasionally in whole-milk products (Weckel and Chicoye, 1954; Whited et al., 2002). Consumers detected no differences in oil-soluble vitamin concen-

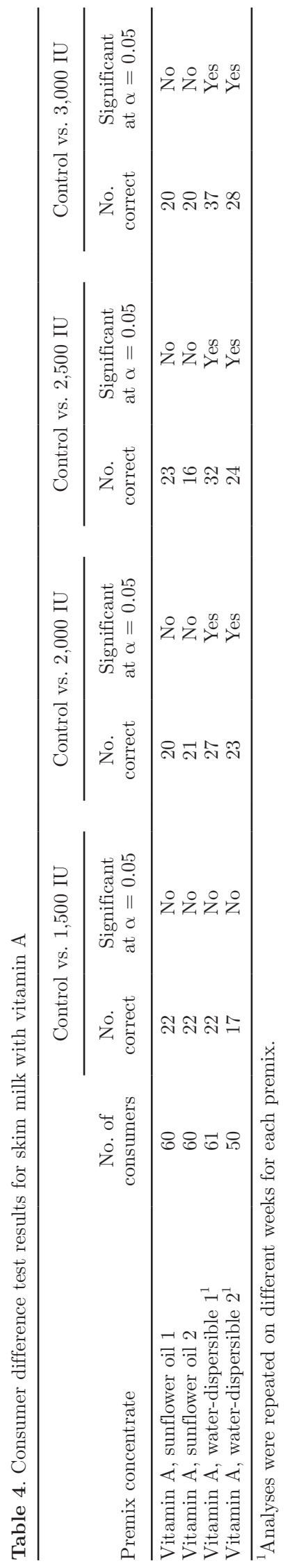


trate treatments. This may have been due to flavor protection from the oil matrices, which have been shown to have protective effects with respect to vitamin A stability by delaying its oxidative degradation and degradation components (Dary and Mora, 2002; Loveday and Singh, 2008). A previous study with triangle tests indicated that light-induced off flavor was distinguished in skim milks with water-based vitamin $\mathrm{A}$ at 2,000 IU after $6 \mathrm{~h}$ of light exposure, and that off flavor in skim milks with oil-based vitamin A at 2,000 IU could not be distinguished until after $24 \mathrm{~h}$ of light exposure (Fellman et al., 1991). The results from that study suggest that vitamin A degradation in the presence of light may also accelerate light-oxidized flavor in milk and should be addressed in future studies.

Quantitation of Selected Volatile Compounds in Fortified Fluid Milk. Quantitation of the 8 selected volatile compounds in fortified fluid milk were consistent with sensory and consumer results. Consumers and trained panelists were able to detect flavor differences in skim milks fortified with water-soluble vitamin A at $2,000,2,500$ and 3,000 IU. Trained panelists documented the flavor as sweet, perfumey, and carrot-like. $\beta$-Ionone (fruity, floral) was found in the same milks above the sensory threshold (mean $=109-218 \mu \mathrm{g} / \mathrm{kg}$ ). Consumers and trained panelists also detected flavor differences in skim milks fortified with water-soluble vitamin $\mathrm{A}$ and $\mathrm{D}$ at $2,000 / 400 \mathrm{IU}, 3,000 / 600 \mathrm{IU}, 4,000 / 800 \mathrm{IU}$, and $6,000 / 1,200$ IU. $\beta$-Ionone was also detected at concentrations above the sensory threshold concentrations in all of these skim milks (mean $=61-98 \mu \mathrm{g} / \mathrm{kg}$ ). Trained panelists were able to detect faint carrot flavor in skim milks fortified with oil-soluble vitamin A at the highest concentration (3,000 IU) and skim milks fortified with oil-soluble vitamin $\mathrm{A}$ and $\mathrm{D}$ at the highest concentration $(6,000 / 1,200 \mathrm{IU})$. $\beta$-Ionone was also found in these milks above the sensory threshold (mean $=71-83 \mu \mathrm{g}$ / $\mathrm{kg}$ ). Of the selected volatile compounds, $\beta$-ionone was detected most frequently and was found in all milks fortified with vitamin A (oil and water) and vitamin $\mathrm{A}$ and D (results not shown). Consumers and trained panelists did not detect flavor differences in $2 \%$ fat milks. $\beta$-Damascone and $\beta$-ionone have been reported as vitamin A thermal degradation products (Suyama et al., 1983; Enzell, 1985; Kanasawud and Crouzet, 1990; Crouzet and Kanasawud, 1992; Kim et al., 2000), and vitamin A light oxidation products (Budowski and Bondi, 1960; Gaylord et al., 1986; Litzenburger and Bernhardt, 2016). This was consistent with our finding of these compounds in milks fortified with vitamin A and vitamin A and D. Trained panelists and consumers did not detect any flavor differences in milks fortified with vitamin $\mathrm{D}$, even at the highest concentration $(1,200 \mathrm{IU})$, about $300 \%$ of the recommended fortifica- 
tion level (400 IU per quart). This finding suggests that it is possible to increase fortification levels in fluid milk products to improve dietary vitamin $\mathrm{D}$ intake in the United States without affecting fluid milk flavors.

\section{CONCLUSIONS}

Vitamin concentrates used for fluid milk fortification have very distinct aromas and aroma-active compounds in the sensory detection range at concentrations applied for milk fortification. Vitamin concentrates were characterized by carrot, fruity, citrus, rancid oil, and painty aromas. Key aroma-active compounds in vitamin concentrates were $\beta$-damascone, $\beta$-ionone, $\beta$-phellandrene, isoamyl acetate, $\beta$-cyclocitral, $\alpha$-irone, trans,trans-2,4hexadienal, and trans,trans-2,4-heptadienal. Four of these compounds were above the sensory threshold in the fortified milks. Water-dispersible vitamin premixes had higher sensory aroma intensities and more aromaactive compounds. Consumers could also detect flavor differences in skim milk fortified with water-dispersible vitamin premixes. These findings suggest that vitamin premixes may contribute off flavors in fluid milk, especially in skim milk fortified with water-dispersible vitamins. The dairy industry should reduce the use of water-dispersible vitamin premixes or conduct research to improve the flavor quality of water-dispersible premixes, especially for vitamin A, to improve fluid milk quality.

\section{ACKNOWLEDGMENTS}

Funding was provided in part by the National Dairy Council (Rosemont, IL). The use of trade names does not imply endorsement or lack of endorsement by those not mentioned. The authors are grateful to Jim Murphy (Upstate Niagara Cooperative Inc., Buffalo, NY) for valuable insights.

\section{REFERENCES}

St Angelo, A. J. 1996. Lipid oxidation in foods. Crit. Rev. Food Sci. Nutr. 36:175-224.

AOAC International. 2007a. Determination of cholecalciferol (vitamin $\mathrm{D}_{3}$ ) in selected foods. Method 2002.05. Official Methods of Analysis. 18th ed. AOAC International, Gaithersburg, MD.

AOAC International. 2007b. Determination of retinyl palmitate in fortified fluid milk. Method 2002.06. Official Methods of Analysis. 18th ed. AOAC International, Gaithersburg, MD.

AOAC International. 2012a. Standard method performance requirements for vitamin A in pre-blends, pre-mixes, and pure materials. SMPR 2012.003. Pages 700-701 in Official Methods of Analysis. 19th ed. AOAC International, Gaithersburg, MD.

AOAC International. 2012b. Standard method performance requirements for vitamin $\mathrm{D}_{3}$ in pre-blends, pre-mixes, and pure materials. SMPR 2012.004. Pages 701-702 in Official Methods of Analysis. 19th ed. AOAC International, Gaithersburg, MD. 
American Society for Testing and Materials (ASTM). 2004. Standard practice for determination of odor and taste thresholds by a forced-choice ascending concentration series method of limits. E 679-04. ASTM, Philadelphia, PA.

Banville, C., J. C. Vuillemard, and C. Lacroix. 2000. Comparison of different methods for fortifying Cheddar cheese with vitamin D. Int. Dairy J. 10:375-382.

Bouillon, R., G. Eelen, L. Verlinden, C. Mathieu, G. Carmeliet, and A. Verstuyf. 2006. Vitamin D and cancer. J. Steroid Biochem. Mol. Biol. 102:156-162.

Bravo, A., J. H. Hotchkiss, and T. E. Acree. 1992. Identification of odor-active compounds resulting from thermal oxidation of polyethylene. J. Agric. Food Chem. 40:1881-1885.

Brothersen, C., D. J. McMahon, J. Legako, and S. Martini. 2016. Comparison of milk oxidation by exposure to LED and fluorescent light. J. Dairy Sci. 99:2537-2544.

Budowski, P., and A. Bondi. 1960. Autoxidation of carotene and vitamin A. Influence of fat and antioxidants. Arch. Biochem. 89:66-73.

Ceglia, L. 2009. Vitamin D and its role in skeletal muscle. Curr. Opin. Clin. Nutr. Metab. Care 12:628-633.

Croissant, A. E., S. P. Washburn, L. L. Dean, and M. A. Drake. 2007. Chemical properties and consumer perception of fluid milk from conventional and pasture-based production systems. J. Dairy Sci. 90:4942-4953.

Crouzet, J., and P. Kanasawud. 1992. Formation of volatile compounds by thermal degradation of carotenoids. Methods Enzymol. 213:54-62.

Dary, O., and J. O. Mora. 2002. Food fortification to reduce vitamin A deficiency: International vitamin A consultative group recommendations. J. Nutr. 132:2927S-2933S

DeMan, J. M. 1999. Principles of Food Chemistry. 3rd ed. Aspen Publishers. Gaithersburg, MD.

Di Marzo, L., P. Cree, and D. M. Barbano. 2016. Prediction of fat globule particle size in homogenized milk using Fourier transform midinfrared. J. Dairy Sci. 99:8549-8560.

Doleschall, F., K. Recseg, Z. Kemeny, and K. Kovari. 2003. Comparison of differently coated SPME fibers applied for monitoring volatile substances in vegetable oils. Eur. J. Lipid Sci. Technol. 105:333-338

Enzell, C. 1985. Biodegradation of carotenoids - an important route to aroma compounds. Pure Appl. Chem. 57:693-700.

Fellman, R. L., P. S. Dimick, and R. Hollender. 1991. Photooxidative stability of vitamin A fortified $2 \%$ lowfat milk and skim milk. J. Food Prot. 54:113-116.

Frankel, E. N. 1983. Volatile lipid oxidation products. Prog. Lipid Res. $22: 1-33$.

Frankel, E. N. 1985. Chemistry of autoxidation: Mechanism, products, and flavor significance. Pages 1-37 in Flavor Chemistry of Fats and Oils. AOCS Press, Champaign, IL.

Friedrich, J. E., and T. E. Acree. 2002. Analyzing carotenoid-derived aroma compounds using gas chromatography-olfactometry. Pages 67-74 in Carotenid-Derived Aroma Compounds. American Chemical Society, Washington, DC.

Garland, C. F., F. C. Garland, E. D. Gorham, M. Lipkin, H. Newmark, S. B. Mohr, and M. F. Holick. 2006. The role of vitamin D in cancer prevention. Am. J. Public Health 96:252-261.

Gaylord, A. M., J. J. Warthesen, and D. E. Smith. 1986. Effect of fluorescent light on the isomerization of retinyl palmitate in skim milk. J. Food Sci. 51:1456-1458.

Grant, W. B., C. F. Garland, and E. D. Gorham. 2007. An estimate of cancer mortality rate reductions in Europe and the U.S. with $1,000 \mathrm{IU}$ of oral vitamin D per day. Recent Results Cancer Res. 174:225-234.

Grosch, W. 1987. Reactions of hydroperoxides-products of low molecular weight. Pages 95-139 in Autoxidation of Unsaturated Lipids. Academic Press, London.

Hanson, A. L., and L. E. Metzger. 2010. Evaluation of increased vitamin $\mathrm{D}$ fortification in high temperature short time processed $2 \%$ milk, UHT processed $2 \%$ fat chocolate milk and low fat strawberry yogurt. J. Dairy Sci. 93:801-807.
Hartman, A. M., and L. P. Dryden. 1974. The vitamins in milk and milk products. Pages 325-401 in Fundamentals of Dairy Chemistry. 2nd ed. B. H. Webb and A. H. Johnson, ed. AVI Publishing Co., Westport, CT.

Hooper, F. C., and A. D. Ayres. 1950. The enzymatic degradation of ascorbic acid. Part I-The inhibition of the enzymatic oxidation of ascorbic acid by substances occurring in black currents. J. Sci. Food Agric. 1:5-8.

Kanasawud, P., and J. C. Crouzet. 1990. Mechanism of formation of volatile compounds by thermal degradation of carotenoids in aqueous medium. $\beta$-carotene degradation. J. Agric. Food Chem. 38:237-243.

Karatapanis, A. E., A. V. Badeka, K. A. Riganakos, I. N. Savvaidis, and M. G. Kontominas. 2006. Changes in flavor volatiles of whole pasteurized milk as affected by packaging material and storage time. Int. Dairy J. 16:750-761.

Kaylegian, K. E, G. E. Houghton, J. M. Lynch, J. R. Fleming, and D. M. Barbano. 2006a. Calibration of infrared milk analyzers: Modified milk versus producer milk. J. Dairy Sci. 89:2817-2832.

Kaylegian, K. E., J. M. Lynch, G. E. Houghton, J. R. Fleming, and D. M. Barbano. 2006b. Modified versus producer milk calibration: Mid-infrared analyzer performance validation. J. Dairy Sci. 89:2833-2845.

Kazmi, S. A., R. Vieth, and D. Rousseau. 2007. Vitamin D3 fortification and quantification in processed dairy products. Int. Dairy J. 17:753-759.

Keszler, A., K. Heberger, and M. Gude. 1998. Identification of volatile compounds in sunflower oil by headspace SPME and ion-trap GC/ MS. J. High Resolut. Chromatogr. 21:368-370.

Keszler, A., T. Kriska, and A. Nemeth. 2000. Mechanism of volatile compound production during storage of sunflower oil. J. Agric. Food Chem. 48:5981-5985.

Kim, M. K., S. L. Drake, and M. A. Drake. 2011. Evaluation of key flavor compounds in reduced- and full-fat cheddar cheeses using sensory studies on model systems. J. Sens. Stud. 26:278-290.

Kim, Y. S., E. Strand, R. Dickmann, and J. Warthesan. 2000. Degradation of vitamin A palmitate in corn flakes during storage. J. Food Sci. 65:1-4.

King, J. M., and D. B. Min. 2002. Riboflavin-photosensitized singlet oxygen oxidation product of vitamin $\mathrm{D}_{2}$. J. Am. Oil Chem. Soc. 79:983-987.

Kutsky, R. J., ed. 1981. Vitamin D. Page 191 in Handbook of Vitamins, Minerals and Hormones. Van Nostrand Reinhold Co., New York, NY.

Leksrisompong, P., D. M. Barbano, A. E. Foegeding, P. Gerard, and M. A. Drake. 2010. The roles of fat and $\mathrm{pH}$ on the detection thresholds and partition coefficients of three compounds: Diacetyl, $\delta$-decalactone and furaneol. J. Sens. Stud. 25:347-370.

Litzenburger, M., and R. Bernhardt. 2016. Selective oxidation of carotenoid-derived aroma compounds by CYP260B1 and CYP267B1 from Sorangium cellosum So ce56. Appl. Microbiol. Biotechnol. 100:4447-4457.

Loveday, S. M., and H. Singh. 2008. Recent advances in technologies for vitamin A protection in foods. Trends Food Sci. Technol. 19:657-668.

McCarthy, K. S., K. Lopetcharat, and M. A. Drake. 2017. Milkfat threshold determination and the effect of milkfat content on consumer preference of fluid milk. J. Dairy Sci. 100:1702-1711.

Meilgaard, M. C., G. V. Civille, and B. T. Carr. 2007. The Spectrum $^{\text {TM }}$ descriptive analysis method. Pages 189-253 in Sensory Evaluation Techniques. CRC Press, Boca Raton, FL.

Mousseron-Cadet, M. 1971. Photochemical transformation of vitamin A. Methods Enzymol. 18C:591-615.

Murphy, S. C., and C. Newcomer. 2001. Guideline for vitamin A and D fortification of fluid milk. Accessed March 8, 2017. http:// phpa.dhmh.maryland.gov/OEHFP/OFPCHS/Milk/Shared\%20 Documents/DPC053_Vitamin_AD_Fortification_Fluid_Milk.pdf.

Nielsen, G. S., and L. Poll. 2006. Determination of odour active aroma compounds in a mixed product of fresh cut iceberg lettuce, carrot and green bell pepper. Dev. Food Sci. 43:517-520. 
National Institute of Standards and Technology (NIST). 2014. Mass spectral database. Accessed Mar. 10, 2105. http://webbook.nist. gov/chemistry/.

Obretenov, C., J. Demyttenaere, K. A. Tehrani, A. Adams, M Kersiene, and N. D. Kimpe. 2002. Flavor release in the presence of melanoidins prepared from L-(+)-ascorbic acid and amino acids. J. Agric. Food Chem. 50:4244-4250.

Ochiai, N., K. Sasamoto, F. David, and P. Sandra. 2016. Solventassisted stir bar sorptive extraction by using swollen polydimethylsiloxane for enhanced recovery of polar solutes in aqueous samples: Application to aroma compounds in beer and pesticides in wine. J. Chromatogr. A 1455:45-56.

Park, C. W., M. A. Stout, and M. A. Drake. 2016. The effect of spraydrying parameters on the flavor of nonfat dry milk and milk protein concentrate 70\%. J. Dairy Sci. 99:9598-9610.

Pasteurized Milk Ordinance (PMO). 2015. Grade A Pasteurized Milk Ordinance 2015 Revision. Accessed Jan. 7, 2015 http://www.fda.gov/downloads/Food/GuidanceRegulation/ GuidanceDocumentsRegulatoryInformation/Milk/UCM513508. pdf.

Prieto, A., O. Basauri, R. Rodil, A. Usobiaga, L. A. Fernandez, N. Etxebarria, and O. Zuloaga. 2010. Stir-bar sorptive extraction: A view on method optimization, novel applications, limitations and potential solutions. J. Chromatogr. A 1217:2642-2666.

Public Health Service. 1940. Milk Ordinance and Code, Recommended by the US Public Health Service, 1939. Public Health Bulletin no. 220. US Government Printing Office, Washington, DC.

Renken, S. A., and J. J. Warthesen. 1993. Vitamin D stability in milk. J. Food Sci. 58:552-555.

Roberts, D. D., P. Pollien, and N. Antille. 2003. Comparison of nosespace, headspace and sensory intensity ratings for the evaluation of flavor absorption by fat. J. Agric. Food Chem. 51:3636-3642.

Schwartz, G. G., and H. G. Skinner. 2007. Vitamin D status and cancer: New insights. Curr. Opin. Clin. Nutr. Metab. Care 10:6-11.

Smith, E. B., D. M. Barbano, J. M. Lynch, and J. R. Fleming. 1995. Infrared analysis of milk: Effect of homogenizer and optical filter selection on apparent homogenization efficiency and repeatability. J. AOAC Int. 78:1225-1233.

Snyder, J. M., E. N. Frankel, and E. Selke. 1985. Capillary gas chromatographic analyses of headspace volatiles from vegetable oils. J. Am. Oil Chem. Soc. 62:1675-1679.

Solinas, M., V. Marsilio, and F. Angerosa. 1987. Behaviour of some components of virgin olive oil flavor in connection with the ripening of olives. Riv. Ital. Sostanze Grasse 64:475-480.
Suyama, K., T. Yeow, and S. Nakai. 1983. Vitamin A oxidation products responsible for haylike flavor production in nonfat dry milk. J. Agric. Food Chem. 31:22-26.

Tippetts, M., S. Martini, C. Brothersen, and D. J. McMahon. 2012. Fortification of cheese with vitamin $\mathrm{D}_{3}$ using dairy protein emulsions as delivery systems. J. Dairy Sci. 95:4768-4774.

van den Dool, H., and P. Kratz. 1963. A generalization of the retention index system including linear programmed gas liquid partition chromatography. J. Chromatogr. 11:463-471.

van Ruth, S. M., J. P. Roozen, and F. J. H. M. Jansen. 2000. Aroma profiles of vegetable oils varying in fatty acid composition vs. concentrations of primary and secondary lipid oxidation products. Nahrung 44:318-322.

Vichi, S., A. I. Castellote, L. Pizzale, L. S. Conte, S. Buxaderas, and E. Lopez-Tamames. 2003. Analysis of virgin olive oil volatile compounds by headspace solid-phase microextraction coupled to gas chromatography with mass spectrometric and flame ionization detection. J. Chromatogr. A 983:19-33.

Wagner, D., D. Rousseau, G. Sidhom, M. Pouliot, P. Audet, and R. Vieth. 2008. Vitamin $\mathrm{D}_{3}$ fortification, quantification, and long term stability in Cheddar and low-fat cheeses. J. Agric. Food Chem. 56:7964-7969.

Weckel, K. G., and E. Chicoye. 1954. Factors responsible for the development of hay-like flavor in vitamin A fortified lowfat milk. J. Dairy Sci. 37:1346-1352.

Wehr, H. M., and J. F. Frank, eds. 2004. Standard Methods for the Examination of Dairy Products. 17th ed. Am. Publ. Health Assoc. Inc., Washington, DC.

Whited, L. J., B. H. Hammond, K. W. Chapman, and K. J. Boor 2002. Vitamin A degradation and light-oxidized flavor defects in milk. J. Dairy Sci. 85:351-354.

Winterhalter, P., and R. Rouseff. 2002. Carotenoid-derived aroma compounds: An introduction. Pages 1-17 in Carotenoid-Derived Aroma Compounds. American Chemical Society, Washington, DC.

Wojciechowski, K. L., C. Melilli, and D. M. Barbano. 2016. A proficiency test system to improve performance of milk analysis methods and produce reference values for component calibration samples for infrared milk analysis. J. Dairy Sci. 99:6808-6827.

Yeh, E. B., D. M. Barbano, and M. A. Drake. 2017. Vitamin fortification of fluid milk. J. Food Sci. In press.

Zile, M. H., and M. E. Cullum. 1983. The function of vitamin A: Current concept. Proc. Soc. Exp. Biol. Med. 172:139-152. 